\title{
Programming implantable cardioverter/defibrillators and outcomes
}

\section{Fritz W. Horlbeck* and Joerg O. Schwab}

\author{
Address: Department of Medicine - Cardiology, University of Bonn, 53105 Bonn, Germany \\ *Corresponding author: Fritz W. Horlbeck (fritz.horlbeck@ukb.uni-bonn.de) \\ Fl000Prime Reports 2015, 7:10 (doi:10.12703/P7-10) \\ All Fl000Prime Reports articles are distributed under the terms of the Creative Commons Attribution-Non Commercial License \\ (http://creativecommons.org/licenses/by-nc/3.0/legalcode), which permits non-commercial use, distribution, and reproduction in any medium, \\ provided the original work is properly cited. \\ The electronic version of this article is the complete one and can be found at: http://f $1000 . c o m / p r i m e / r e p o r t s / m / 7 / / 0$
}

\begin{abstract}
Implantable cardioverter-defibrillators are complex technical devices with a multitude of programming options for the physician. In recent years, numerous randomized trials have been performed to define the optimal programming strategies and have provided valuable insights, especially in primary prevention patients. This article provides an actual overview on the existing evidence on the most important programming features for accurate detection and therapy of ventricular arrhythmias.
\end{abstract}

\section{Introduction}

Implantable cardioverter-defibrillators (ICDs) can prevent sudden cardiac death in patients implanted for primary and secondary prevention. However, inappropriate shock deliveries, most commonly caused by supraventricular tachycardia (SVT), remain a major challenge. Appropriate as well as inappropriate ICD shock delivery is, besides the immediate pain and increase in the rate of hospitalisations, associated with a relevant burden of chronic anxiety and depression $[1,2]$. In addition to a potentially lower quality of life, appropriate as well as inappropriate shocks are associated with increased mortality [3-7]. The frequently mentioned influence of several shock deliveries on the longevity of ICD generators seems to be insignificant [8-10].

Two major options determine the initiation and the characteristics of ICD therapies: the tachycardia detection settings and the type of therapy delivered, that is, antitachycardia pacing (ATP) or high voltage shocks.

In recent years, several important randomized studies have tried to define the ideal programming approach for accurate rhythm detection and the reduction of inappropriate and appropriate ICD shocks. The major findings focussed on ATP therapy,-even rapid ventricular tachycardia, (which was previously widely regarded as too dangerous) - prolonged detection intervals, ventricular detection rate, and dual chamber tachycardia detection mode. Regrettably, there is as yet no published consensus on the form of a therapeutic guideline on the most appropriate programming of ICDs. Furthermore, in the light of the existing evidence, some common default settings of ICD manufacturers should be questioned, for example, numbers of intervals to detect tachyarrhythmias or sustained rate duration.

The current article will provide an update on the state of evidence for modern ICD programming and focus on different strategies to prevent ICD shocks for ventricular as well as supraventricular tachyarrhythmia in order to reduce morbidity.

\section{Antitachycardia pacing for fast ventricular tachycardia}

Generally, fast ventricular tachycardias (FVTs) are regarded as more dangerous. Traditionally, they have been treated by primary shock delivery.

The PainFree I and II trials showed the effectiveness and safety of the application of ATPs (2 sequences of 8-pulse burst pacing train at $88 \%$ of the ventricular tachycardia (VT) cycle length) before shock delivery even on FVT with a heart rate of 188-250 beats per minute (bpm) $[11,12]$. Concerns about efficacy, risk of VT acceleration, and delay of shock therapy have not been confirmed, especially not in modern generation ICDs. In the randomized PainFree II trial, VT acceleration, episode duration, 
syncope, and sudden death were similar between arms. With "ATPonFastVT", the efficacy and safety of two sequences of ATP to terminate FVTs has been demonstrated [13]. Prolongation to a 15-pulse ATP in the ADVANCE-D trial proved to be as effective and safe as the 8-pulse ATP, but was not superior [14]. ATPs for FVT are also effective in cardiac resynchronisation therapy defibrillator (CRT-D) patients. There was no difference between biventricular and right ventricle-delivered ATP in the general population [15]. Programming more than 2 ATP attempts for FVT resulted in only a small increase in successful termination of VT [16]. There is some evidence that burst-ATP is more effective for FVT rates of 188-250 bpm than ramp-ATP [17]. All of the above mentioned studies used burst pacing as the primary ATP attempt.

As shown in Figure 1, ATP was successful from between two-thirds and nearly three-quarters of ventricular episodes in all randomized trials.

\section{Detection intervals}

It has been shown that appropriate ICD therapy delivery exceeds the incidence of sudden cardiac death in control populations by two or three to one [18]. This is partly due to treatment of non-sustained ventricular arrhythmias. Several studies analysed whether increasing the number of intervals of detection (NID) is effective in reducing the burden of unnecessary "appropriate" ICD interventions.

The PREPARE trial evaluated this approach (FVT $\geq 182$ bpm, 30/40 NID) in a non-randomized manner with a cohort of primary prevention patients compared to a historical control group (NID 18/24) and described a significant decrease in ICD interventions for SVT as well as for VT [19]. The RELEVANT study confirmed this finding (12/16 vs. 30/40 NID) for the first time in nonischemic cardiomyopathy (NICM) patients with CRT-D [20]. The MADIT-RIT followed a similar concept with a delayed therapy (60 sec delay at 170-199 bpm, $12 \mathrm{sec}$ delay at 200-249 bpm, and a $2.5 \mathrm{sec}$ delay at $\geq 250 \mathrm{bpm}$ ) and proved its effectiveness in patients with ICDs or CRT-D devices for primary prevention defibrillator therapy [3]. Recently, the large scale randomized ADVANCE III trial confirmed the superiority of a 30/40 interval detection (compared to 18/24) in patients for primary and secondary prevention, including both ischemic (ICM) and non-ischemic cardiomyopathy

Figure I. Antitachycardia pacing (ATP) success rates in selected randomized trials

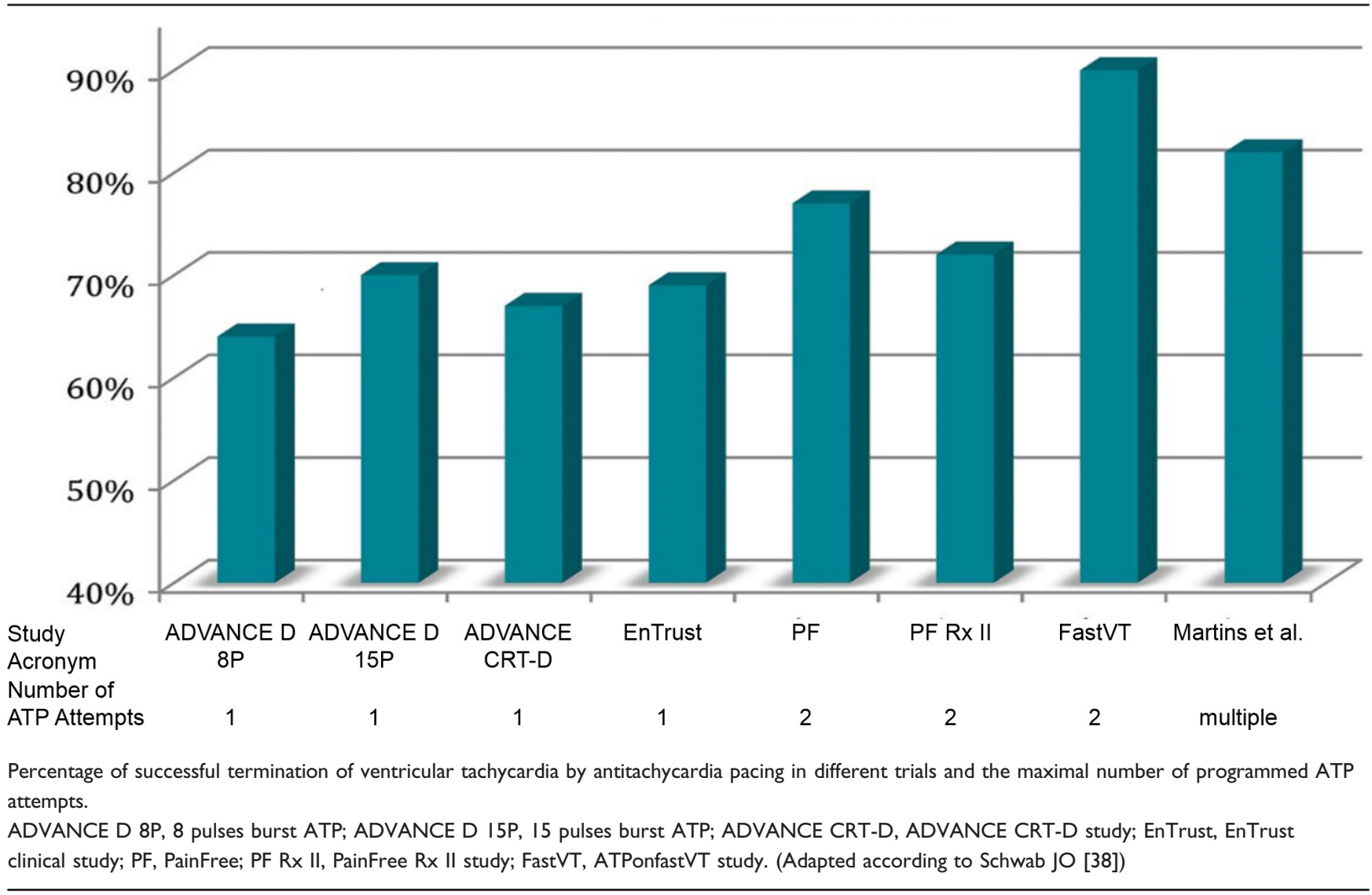


(NICM) [21]. The earlier published PREPARE-Trial reported one death, probably related to the study programming [19]. This case was an initially untreated slow VT in the monitor zone which later accelerated to ventricular fibrillation (VF) and was terminated with the sixth high voltage shock therapy. However, in this non-randomized study, there was a trend of reduced mortality in the treated group. The above mentioned MADIT-RIT, ADVANCE III, and RELEVANT trials did not find any association between prolonged arrhythmia detection and increased mortality.

\section{Detection rate}

In the non-randomized ALTITUDE REDUCES observation study, the lowest risk of appropriate and inappropriate shock was associated with detection rates $\geq 200 \mathrm{bpm}$ [22]. In MADIT-RIT, the setting of a high cut-off rate (heart rate of $\geq 200 \mathrm{bpm}$ combined with a $2.5 \mathrm{sec}$ delay before initiation of therapy) compared with conventional programming $(2.5 \mathrm{sec}$ delay at $170-199 \mathrm{bpm}$ and a $1 \mathrm{sec}$ delay at $\geq 200 \mathrm{bpm}$ ) reduced the first occurrence of inappropriate shocks by nearly $50 \%$ [3]. Because patients with documented permanent or persistent atrial fibrillation, a major risk factor for inappropriate therapies, were excluded from this study, the benefit of high cut-off programming may be influenced by the inclusion criteria $[23,24]$.

The DECREASE study, presented at the American Heart Association (AHA) 2013 meeting, tested a "progressive" ICD programming (187/min for VT and 240/min for VF) against a more conventional programming feature $(171 / \mathrm{min}$ for VT and $214 / \mathrm{min}$ for VF) in a primary prevention ICD population with dual and single chamber ICD devices, CRT-Ds and both ischemic and non-ischemic cardiomyopathy. The higher detection rate resulted in a significant reduction of inappropriate (13\% vs. $6 \%$ ) and appropriate (15\% vs. 9\%) therapy deliveries (ATP + shock) [25]. These results support the concept of using higher VT and VF detection rates with up to $240 \mathrm{bpm}$ (cycle length $250 \mathrm{~ms}$ ). This would include additional activation of all SVT discriminators.

In the recently published PROVIDE trial, a combination of higher detection rates, longer detection intervals, empiric ATP and optimized SVT discriminators reduced the 2-year ICD shock rate to $12.4 \%$ compared to $19.4 \%$ with conventional programming [6]. However, the annual inappropriate shock rate of the study arm (5\%) in this trial was higher than in the DECREASE study (2\%). The majority of inappropriate shocks in the PROVIDE study were triggered by SVTs [6]. This difference may be explained by the upper limit of SVT discrimination (214 bpm).
It was reported that using the "sustained rate duration" algorithm accounted for $18 \%$ of inappropriate ICD therapies [26]. This algorithm can overrule SVT discrimination by enforcing ICD therapy delivery, irrespective of the type of ongoing tachycardia, after a discrete amount of time (e.g. a default setting of 3 mins). Although almost all ICD manufacturers provide this programming feature, it has no significant value in modern ICD programming and should not be applied at all.

It can be summarized that both long detection intervals and increased detection rates for VT/VF are safe. Raising the detection rate of the ICDs not only decreases the rate of false detection with this inappropriate therapy of SVT but also reduces the number of detected VT episodes that do not need ICD intervention.

Subcutaneous ICDs, which are not equipped with the ATP feature, seem to present an increased risk of inappropriate ICD shocks, compared to ICDs with the above mentioned programming. A dual zone programming with activation of SVT discrimination in these devices resulted in a reduced shock rate [27].

Special attention has to be paid to young individuals with primary electrical diseases (e.g. Brugada or long QT syndrome). A single detection zone with a VF zone starting at $230 \mathrm{bpm}$, including a long detection interval to avoid treatment of self-terminating VTs or Torsades de pointes tachycardia is recommended. In patients with bradycardia induced ventricular tachycardia syndromes (e.g. LQT- Type 3), atrial pacing may be used with a sufficiently high lower rate limit [28].

\section{Detection mode}

For a long time, there has been controversy about whether dual chamber (DC) ICDs are superior to single chamber (SC) ICD tachycardia detection. Concerns have been raised that the implantation of DC ICDs might increase complication rates and, with this, mortality in comparison to SC ICDs $[29,30]$. However, other factors that reflect an impaired cardiac condition may influence the choice of ICD device type. This can be the presence of atrial fibrillation or the need for antibradycardia pacing.

Friedman et al. showed that DC detection significantly decreases inappropriate detection of SVTs compared with SC programming [31]. In the non-randomized ALTITUDE REDUCES study, dual-zone programming was associated with a reduction in the incidence of appropriate and inappropriate shocks, but only for detection rates $<200 \mathrm{bpm}$ [22]. Other studies found no benefits or only small benefits for DC defibrillators [32-34]. 
The recently presented OPTION-Trial is the first large prospective randomized study that questions whether DC tachycardia detection algorithms reduce the risk of inappropriate shocks in comparison to SC detection [35]. The study used two ATP sequences followed by shocks at tachycardia rates of 170-200 bpm, and only one ATP setting with subsequent shock delivery for tachycardia rates above $200 \mathrm{bpm}$. The patient follow-up lasted 27 months. DC discrimination (combined with algorithms to minimize ventricular pacing) significantly reduced the risk of first inappropriate shocks to $4.3 \%$, compared to $10.3 \%$ in the $\mathrm{SC}$ detection group. The annual incidence of inappropriate shocks $(2.6 \%$ in DC ICDs) was similar when compared to patients in the MADIT-RIT trial, but much lower than in several earlier large-scale trials that reported inappropriate shock rates of up to $11 \%[3,5,6,19,23,31,32,36]$.

The DECREASE study also showed an additional benefit for DC detection vs. SC detection, when combined with progressive detection settings to reduce inappropriate shocks [25].

\section{Impact of ICD shocks on mortality}

The connection between appropriate shocks and mortality is well known and might be explained in part by the fact that worsening heart failure promotes the occurrence of VT/VF and consecutively shock delivery. Thus, appropriate ICD shocks probably indicate a risk of heart failure rather than induce heart failure per se [5]. A harmful effect of inappropriate ICD shocks on mortality has also been discussed after MADIT II $[23,37]$. Worsening heart failure, besides increasing the incidence of ventricular arrhythmias, may also lead to more atrial fibrillation and sinus tachycardia that produces inappropriate shock delivery.

However, only appropriate and inappropriate shocks were associated with increased mortality, whereas appropriate and inappropriate ATP was not. The prognostic relevance of the significant reduction in inappropriate and appropriate ATP by high rate programming remains unclear. Concerning the prognosis, the difference between ATPs and shocks has been confirmed by a 2010 meta-analysis (Figure 2) [4].

In the above mentioned studies, neither the use of ATP for FVT nor the prolongation of detection intervals or higher cut-off rates of the VT/VF settings resulted in an increase of syncope events. The MADIT-RIT as well as the PROVIDE study showed that optimization of ICD programming

Figure 2. Differences in effects of electrical therapy type for ventricular arrhythmias on mortality

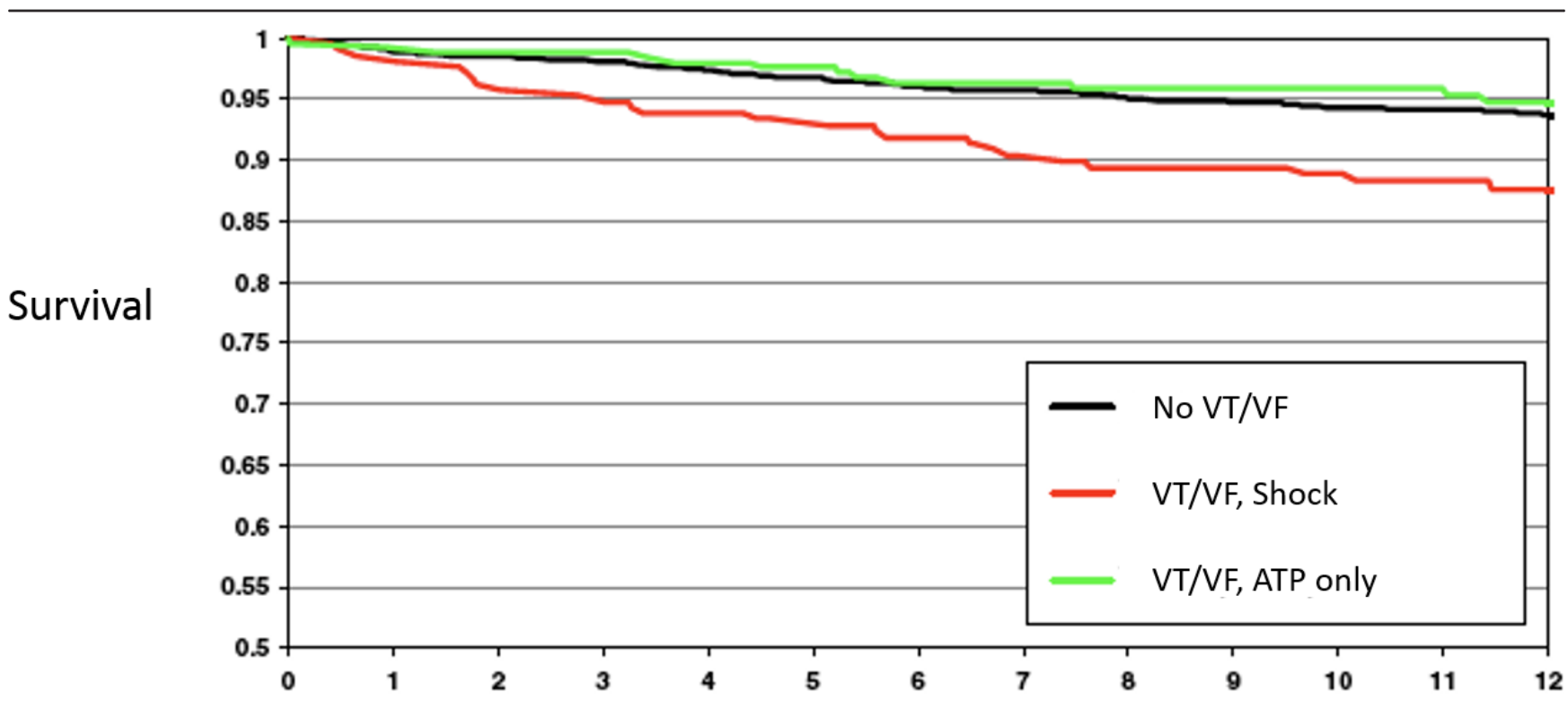

Follow up (Months)

Survival rates by ventricular rhythm and therapy type. Survival among patients who received appropriate defibrillator shocks was significantly worse than among patients with no ventricular tachycardia/fibrillation or among patients treated with ATPs only. The latter groups showed a similar survival. ATP, antitachycardia pacing; VT, ventricular tachycardia; VF, ventricular fibrillation (Adapted according to Sweeney et al. [4]) 
with consecutive reduction of inappropriate shocks was associated with a significant reduction in total mortality. In contrast, the risk of overall mortality in the OPTION and DECREASE studies, which also showed a significantly reduced occurrence of inappropriate shocks, was not reduced. The reason for this remains to be established, but may be due to the different patient populations studied.

In summary, the impact of inappropriate shocks as well as high numbers of ATP on mortality is not completely understood. However, despite the questionable negative effect of inappropriate shocks, every effort should be made to reduce inappropriate ICD intervention by applying new algorithms with prolonged detection intervals and higher VT cut-off rates.

\section{Conclusion}

Currently, modern ICD devices provide many antitachycardia programming features, which are able to reduce morbidity and, in some settings, mortality. The EMPIRIC trial failed to prove the superiority of a patient-specific, physician-tailored ICD programming to a standardized empiric ICD programming [36]. This was mostly due to the underuse of ATP therapy, which led to an excess in inappropriate ICD shocks in the physician-tailored cohort.

Particularly with primary prevention ICD indication, avoiding inappropriate and unnecessary shock delivery is mandatory.

In primary prevention patients, the risk of appropriate and inappropriate shocks can be safely reduced by a dual detection zone with VT detection rates above $188 \mathrm{bpm}$ or even $\geq 200$ bpm $[3,11-13,22]$. The VF zone with shockonly therapy may be programmed as high as $240 \mathrm{bpm}$, including activation of SVT discriminators [13].

We recommend the use of ATP as the first-line ICD intervention in a FVT-zone ranging from 188 to $240 \mathrm{bpm}$, preferably with one or two sequences of 8-pulse burst pacing train at $88 \%$ of the VT cycle length interval [11-17].

The prolongation of VT detection intervals (e.g. 30/40 NID) further reduces unnecessary ICD intervention due to self-terminating tachycardias without a higher risk of syncope $[3,19-21]$.

The "sustained rate duration" algorithm does not add significant benefit to modern ICD programming and should be turned off by default.

In primary and secondary prevention, activation of DC algorithms seems to be helpful to reduce inappropriate shocks. But it is important to use optimal tachyarrhythmia discrimination, together with optimized anti-bradycardia settings, to avoid unnecessary ventricular pacing, especially in heart failure individuals.

We strongly support patient-adjusted ICD programming recommendations by the European Heart Rhythm Association (EHRA) as well as Heart Rhythm Society (HRS).

\section{Abbreviations}

ATP, antitachycardia pacing; bpm, beats per minute; CRT, cardiac resynchronisation therapy; CRT-D, cardiac resynchronisation therapy defibrillator, CRT-D; DC, dual chamber; FVT, fast ventricular tachycardia; ICD, implantable cardioverter/defibrillator; ICM, ischemic cardiomyopathy; NICM, non-ischemic cardiomyopathy; NID, number of intervals to detect; SC, single chamber; SVT, supraventricular tachycardia; VF, ventricular fibrillation; $\mathrm{VT}$, ventricular tachycardia.

\section{Disclosures}

Joerg Schwab received research grants and travel support from Biotronik, St. Jude Medical, Boston Scientific, and Sorin.

\section{Acknowledgments}

The authors would like to thank Daniele Raffaele Gambone, translator, for revision of the manuscript.

\section{References}

I. Bourke JP, Turkington D, Thomas G, McComb JM, Tynan M: Florid psychopathology in patients receiving shocks from implanted cardioverter-defibrillators. Heart 1997, 78:58।-3.

2. Mark DB, Anstrom KJ, Sun JL, Clapp-Channing NE, Tsiatis AA, Davidson-Ray L, Lee KL, Bardy GH: Quality of life with defibrillator therapy or amiodarone in heart failure. $N$ Engl J Med 2008, 359:999-1008.

3. Moss AJ, Schuger C, Beck CA, Brown MW, Cannom DS, Daubert JP, Estes, NA Mark, Greenberg H, Hall WJ, Huang DT, Kautzner J, Klein H, McNitt S, Olshansky B, Shoda M, Wilber D, Zareba W: Reduction in inappropriate therapy and mortality through ICD programming. N Engl J Med 20I2, 367:2275-83.

FlOOOPrime

RECOMMENDED

4. Sweeney MO, Sherfesee L, DeGroot PJ, Wathen MS, Wilkoff BL: Differences in effects of electrical therapy type for ventricular arrhythmias on mortality in implantable cardioverter-defibrillator patients. Heart Rhythm 2010, 7:353-60.

\section{FlOOOPrime}

\section{RECOMMENDED}

5. Poole JE, Johnson GW, Hellkamp AS, Anderson J, Callans DJ, Raitt MH, Reddy RK, Marchlinski FE, Yee R, Guarnieri T, Talajic M, Wilber DJ, Fishbein DP, Packer DL, Mark DB, Lee KL, Bardy GH: Prognostic importance of defibrillator shocks in patients with heart failure. N Engl J Med 2008, 359:1009-I7.

\section{FlOOOPrime} RECOMMENDED

6. Saeed M, Hanna I, Robotis D, Styperek R, Polosajian L, Khan A, Alonso J, Nabutovsky Y, Neason C: Programming implantable cardioverter-defibrillators in patients with primary 
prevention indication to prolong time to first shock: results from the PROVIDE study. J Cardiovasc Electrophysiol 20 I4, 25:52-9.

\section{FlOOOPrime}

7. van Rees, Johannes B, Borleffs, C Jan Willem, de Bie, Mihály K, Stijnen T, van Erven L, Bax J], Schalij MJ: Inappropriate implantable cardioverter-defibrillator shocks: incidence, predictors, and impact on mortality. J Am Coll Cardiol 20I I, 57:556-62.

\section{FlOOOPrime}

\section{RECOMMENDED}

8. Horlbeck FW, Mellert F, Kreuz J, Nickenig G, Schwab JO: Realworld data on the lifespan of implantable cardioverterdefibrillators depending on manufacturers and the amount of ventricular pacing. J Cardiovasc Electrophysiol 2012, 23:I336-42.

9. Schaer BA, Koller MT, Sticherling C, Altmann D, Joerg L, Osswald S: Longevity of implantable cardioverter-defibrillators, influencing factors, and comparison to industry-projected longevity. Heart Rhythm 2009, 6:1737-43.

10. Thijssen J, Borleffs, C Jan Willem, van Rees, Johannes B, Man S, de Bie, Mihály K, Venlet J, van der Velde, Enno T, van Erven L, Schalij MJ: Implantable cardioverter-defibrillator longevity under clinical circumstances: an analysis according to device type, generation, and manufacturer. Heart Rhythm 2012, 9:5 I3-9.

II. Wathen MS, DeGroot PJ, Sweeney MO, Stark Al, Otterness MF, Adkisson WO, Canby RC, Khalighi K, Machado C, Rubenstein DS, Volosin KJ: Prospective randomized multicenter trial of empirical antitachycardia pacing versus shocks for spontaneous rapid ventricular tachycardia in patients with implantable cardioverter-defibrillators: Pacing Fast Ventricular Tachycardia Reduces Shock Therapies (PainFREE Rx II) trial results. Circulation 2004, I 1 0:259|-6.

\section{FlOOOPrime \\ RECOMMENDED}

12. Wathen MS, Sweeney MO, DeGroot PJ, Stark AJ, Koehler JL, Chisner MB, Machado C, Adkisson WO: Shock reduction using antitachycardia pacing for spontaneous rapid ventricular tachycardia in patients with coronary artery disease. Circulation 200I, I04:796-80I.

\section{FlOOOPrime
RECOMMENDED}

13. Schwab Jea: First results of the ATPonFastVT-study. Heart Rhythm 201 I; Supplement S2 20II.

14. Santini M, Lunati $M$, Defaye $P$, Mermi J, Proclemer A, del CastilloArroys S, Molon G, Santi E, Santo T de, Navarro X, Kloppe A: Prospective multicenter randomized trial of fast ventricular tachycardia termination by prolonged versus conventional anti-tachyarrhythmia burst pacing in implantable cardioverterdefibrillator patients-Atp DeliVery for pAiNless ICD thErapy (ADVANCE-D) Trial results. J Interv Card Electrophysiol 2010, 27: $127-35$.

\section{FlOOOPrime \\ RECOMMENDED}

15. Gasparini M, Anselme F, Clementy J, Santini M, Martinez-Ferrer J, De Santo T, Santi E, Schwab JO, Investigators AC-D: BIVentricular versus right ventricular antitachycardia pacing to terminate ventricular tachyarrhythmias in patients receiving cardiac resynchronization therapy: the ADVANCE CRT-D Trial. Am Heart J 2010, I59:1 I 16-II23 el II 2 .

16. Martins RP, Blangy H, Muresan L, Freysz L, Groben L, Zinzius P, Schwartz J, Sellal J, Aliot E, Sadoul N: Safety and efficacy of programming a high number of antitachycardia pacing attempts for fast ventricular tachycardia: a prospective study. Europace 2012, I4:1457-64.

17. Gulizia MM, Piraino L, Scherillo M, Puntrello C, Vasco C, Scianaro MC, Mascia F, Pensabene O, Giglia S, Chiarandà G, Vaccaro I, Mangiameli S, Corrao D, Santi E, Grammatico A: A randomized study to compare ramp versus burst antitachycardia pacing therapies to treat fast ventricular tachyarrhythmias in patients with implantable cardioverter defibrillators: the PITAGORA ICD trial. Circ Arrhythm Electrophysiol 2009, 2:146-53.

\section{FIOOOPrime
RECOMMENDED}

18. Germano J, Reynolds M, Essebag V, Josephson ME: Frequency and causes of implantable cardioverter-defibrillator therapies: is device therapy proarrhythmic? Am J Cardiol 2006, 97:|255-6I.

19. Wilkoff BL, Williamson BD, Stern RS, Moore SL, Lu F, Lee SW, Birgersdotter-Green UM, Wathen MS, Van Gelder, Isabelle C, Heubner BM, Brown ML, Holloman KK: Strategic programming of detection and therapy parameters in implantable cardioverter-defibrillators reduces shocks in primary prevention patients: results from the PREPARE (Primary Prevention Parameters Evaluation) study. J Am Coll Cardiol 2008, 52:54I-50.

\section{FlOOOPrime}

20. Gasparini M, Menozzi C, Proclemer A, Landolina M, lacopino S Carboni A, Lombardo E, Regoli F, Biffi M, Burrone V, Denaro A Boriani G: A simplified biventricular defibrillator with fixed long detection intervals reduces implantable cardioverter defibrillator (ICD) interventions and heart failure hospitalizations in patients with non-ischaemic cardiomyopathy implanted for primary prevention: the RELEVANT [Role of long dEtection window programming in patients with LEft VentriculAr dysfunction, Non-ischemic eTiology in primary prevention treated with a biventricular [CD] study. Eur Heart J 2009, 30:2758-67.

FlOOOPrime

21. Gasparini M, Proclemer A, Klersy C, Kloppe A, Lunati M, Ferrer, José Bautista Martìnez, Hersi A, Gulaj M, Wijfels, Maurits CEF, Santi E, Manotta L, Arenal A: Effect of long-detection interval vs standard-detection interval for implantable cardioverterdefibrillators on antitachycardia pacing and shock delivery: the ADVANCE III randomized clinical trial. JAMA 20I3, 309: |903-II.

\section{FlOOOPrime \\ RECOMMENDED}

22. Gilliam FR, Hayes DL, Boehmer JP, Day J, Heidenreich PA, Seth M, Jones PW, Stein KM, Saxon LA: Real world evaluation of dualzone ICD and CRT-D programming compared to single-zone programming: the ALTITUDE REDUCES study. J Cardiovasc Electrophysiol 2011, 22:1023-9.

\section{FlOOOPrime}

\section{RECOMMENDED}

23. Daubert JP, Zareba W, Cannom DS, McNitt S, Rosero SZ, Wang P, Schuger C, Steinberg JS, Higgins SL, Wilber DJ, Klein H, Andrews ML, Hall WJ, Moss AJ: Inappropriate implantable cardioverterdefibrillator shocks in MADIT II: frequency, mechanisms, predictors, and survival impact. J Am Coll Cardiol 2008, 5 I: |357-65.

\section{FlOOOPrime \\ RECOMMENDED}

24. Fischer A, Ousdigian KT, Johnson JW, Gillberg JM, Wilkoff BL: The impact of atrial fibrillation with rapid ventricular rates and device programming on shocks in I06,5I3 ICD and CRT-D patients. Heart Rhythm 2012, 9:24-31.

\section{FlOOOPrime}

25. Schwab JO, Bonnemeier H, Kleemann T, Brachmann J, Fischer S, Birkenhauer F, Eberhardt F, Investigators ftDS: Reduction of inappropriate ICD therapies in patients with primary prevention of sudden cardiac death: DECREASE-study. $A H A$ 2013, Late breaking Trials.

26. Leenhardt A, Defaye P, Mouton E, Delay M, Delarche N, Dupuis J, Bizeau O, Mabo P, Cheggour S, Babuty D: First inappropriate implantable cardioverter defibrillator therapy is often due to 
inaccurate device programming: analysis of the French OPERA registry. Europace 2012, I4:|465-74.

\section{FIOOOPrime}

27. Weiss R, Knight BP, Gold MR, Leon AR, Herre JM, Hood M, Rashtian M, Kremers M, Crozier I, Lee KL, Smith W, Burke MC: Safety and efficacy of a totally subcutaneous implantablecardioverter defibrillator. Circulation 2013, I 28:944-53.

\section{FlOOOPrime \\ RECOMMENDED}

28. Viskin S: Cardiac pacing in the long QT syndrome: review of available data and practical recommendations. J Cardiovasc Electrophysiol 2000, I I:593-600.

29. Dewland TA, Pellegrini CN, Wang Y, Marcus GM, Keung E, Varosy PD: Dual-chamber implantable cardioverter-defibrillator selection is associated with increased complication rates and mortality among patients enrolled in the NCDR implantable cardioverter-defibrillator registry. I Am Coll Cardiol 201I, 58:1007-13.

30. Wilkoff BL, Cook JR, Epstein AE, Greene HL, Hallstrom AP, Hsia H, Kutalek SP, Sharma A: Dual-chamber pacing or ventricular backup pacing in patients with an implantable defibrillator: the Dual Chamber and VVI Implantable Defibrillator (DAVID) Trial. JAMA 2002, 288:3।I5-23.

31. Friedman PA, McClelland RL, Bamlet WR, Acosta H, Kessler D, Munger TM, Kavesh NG, Wood M, Daoud E, Massumi A, Schuger C, Shorofsky S, Wilkoff B, Glikson M: Dual-chamber versus single-chamber detection enhancements for implantable defibrillator rhythm diagnosis: the detect supraventricular tachycardia study. Circulation 2006, I I3:287|-9.

32. Theuns, Dominic AMJ, Rivero-Ayerza M, Boersma E, Jordaens L: Prevention of inappropriate therapy in implantable defibrillators: A meta-analysis of clinical trials comparing single-chamber and dual-chamber arrhythmia discrimination algorithms. Int J Cardiol 2008, I 25:352-7.

33. Friedman PA, Bradley D, Koestler C, Slusser J, Hodge D, Bailey K, Kusumoto F, Munger TM, Militanu A, Glikson M: A prospective randomized trial of single- or dual-chamber implantable cardioverter-defibrillators to minimize inappropriate shock risk in primary sudden cardiac death prevention. Europace 2014, 16:1460-8.

34. Ruwald $A H$, Sood $N$, Ruwald $M H$, Jons C, Clyne CA, McNitt S, Wang $\mathrm{P}$, Zareba W, Moss AJ: Frequency of inappropriate therapy in patients implanted with dual-versus singlechamber ICD devices in the ICD arm of MADIT-CRT. J Cardiovasc Electrophysiol 2013, 24:672-9.

35. Kolb C, Sturmer M, Sick P, Reif S, Davy JM, Molon G, Schwab JO, Mantovani G, Dan D, Lennerz C, Borri-Brunetto A, Babuty D: Reduced risk of inappropriate ICD shocks with dual-chamber therapy compared with single-chamber therapy - results of the randomized OPTION study. JACC Heart Failure 2014, 2:611-9.

36. Wilkoff BL, Ousdigian KT, Sterns LD, Wang ZJ, Wilson RD, Morgan JM: A comparison of empiric to physician-tailored programming of implantable cardioverter-defibrillators: results from the prospective randomized multicenter EMPIRIC trial. J Am Coll Cardiol 2006, 48:330-9.

\section{FlOOPrime}

\section{RECOMMENDED}

37. Raitt $\mathrm{MH}$ : Implantable cardioverter-defibrillator shocks: a double-edged sword? J Am Coll Cardiol 2008, 5 I: I366-8.

38. Schwab JO: Antitachycardia pacing to terminate ventricular tachyarrhythmia: new insights into how to reduce painful implantable cardioverter defibrillator shocks. Europace 2012, 14:|38|-2. 